\title{
A novel protein of Erysipelothrix rhusiopathiae that confers haemolytic activity on Escherichia coli
}

\author{
Sou-ichi Makino, Ken Katsuta† and Toshikazu Shirahata
}

Department of Veterinary Microbiology, Obihiro University of Agriculture and Veterinary Medicine, Obihiro, Hokkaido 080-8555, Japan

\author{
Author for correspondence: Sou-ichi Makino. Tel: +8115549 5386. Fax: +81155495402 \\ e-mail: smakino@obihiro.ac.jp
}

\begin{abstract}
Erysipelothrix rhusiopathiae, the cause of swine erysipelas and human erysipeloid, produces a haemolysin. A recombinant plasmid, pHLY, conferring haemolytic activity on Escherichia coli was isolated from a genomic library of Ery. rhusiopathiae strain Tama-96. This plasmid was stable in RecA-E. coli, but unstable in a RecA+ strain. A spontaneous deletion plasmid, pMini-HLY, also conferring haemolytic activity was derived from PHLY. Two ORFs were detected in pHLY. Analysis of pMini-HLY and other deletion clones established that ORF2 was associated with haemolytic activity. The sequence of ORF1 was highly homologous to those of transposases in the IS30 family. The deletion which generated pMini-HLY was between two short direct repeat (DR) sequences flanking the ORF1 sequence, and there were inverted repeat sequences inside the two DR sequences, suggesting an insertion element. No sequence homology to the deduced amino acid sequence of ORF2 was detected in the databases, but its sequence was characteristic of a surface lipoprotein. Western blot analysis, using antiserum against the $16 \mathrm{kDa}$ protein produced from ORF2, found the protein to be commonly distributed in all Erysipelothrix species.
\end{abstract}

Keywords: Erysipelothrix rhusiopathiae, haemolysis, transposase, IS30

\section{INTRODUCTION}

Erysipelothrix rhusiopathiae causes erysipelas in swine and a variety of diseases in other animals, as well as erysipeloid, a human skin disease (Wood, 1984). Erysipelas can occur as an acute septicaemia or chronic disease with development of arthritic lesions and endocarditis and continues to be a major cause of economic loss in swine-producing areas of the world. Much of the interest in Ery. rhusiopathiae is due to the chronic and progressive character of the arthritic lesions in pigs, which superficially resemble those of human rheumatoid arthritis. However, the pathogenesis of these lesions remains unclear.

Erysipelothrix species form a weak haemolytic zone $(\alpha-$ haemolysis) on blood agar plates. In many pathogenic

\footnotetext{
+ Present address: National Institute of Animal Health, Tsukuba Science City, Ibaraki 305-0856, Japan.
}

Abbreviation: $\mathrm{DR}$, direct repeat.

The DDBJ accession number for the sequence described in this paper is $A B 017185$. bacteria haemolysins are involved in virulence (Stanley et al., 1998). The haemolysin (listeriolysin) in Listeria monocytogenes, which is phylogenetically closely related to Ery. rhusiopathiae, is essential for intracellular survival (Bielecki et al., 1990). The aim of this work was to identify the gene encoding the haemolysin of Ery. rhusiopathiae and to compare this haemolysin to haemolysins in other pathogenic bacteria.

\section{METHODS}

Bacterial strains and media. Table 1 lists the Erysipelothrix strains used in this study. Ery. rhusiopathiae Tama-96 was used as the basis for construction of a genomic library. Escherichia coli MC1061 was used as a host strain to maintain recombinant plasmids. E. coli HB101 was used as a RecA ${ }^{-}$ strain. Brain Heart Infusion broth (BHI; Difco) supplemented with $0 \cdot 1 \%(\mathrm{w} / \mathrm{v})$ Tween $80(\mathrm{BHIT})$ and $\mathrm{L}$ broth were used to cultivate the Erysipelothrix and E. coli strains, respectively. When necessary, media were supplemented with $1.5 \%(\mathrm{w} / \mathrm{v})$ agar or the appropriate antibiotic. To examine the haemolytic activity of bacterial cells, we used Columbia agar (BRL) supplemented with $5 \%$ sheep blood (blood agar). 
Table 1. Erysipelothrix strains and their characteristics

All strains were positive for haemolysis, and a $16 \mathrm{kDa}$ protein was detected in Western blots of all cell lysates using anti-Hly.

\begin{tabular}{|c|c|c|c|}
\hline Strain & Serotype & $\begin{array}{c}\text { Southern } \\
\text { hybridization }(\mathbf{k b})^{*}\end{array}$ & Reference \\
\hline \multicolumn{4}{|c|}{ Ery. rhusiopathiae } \\
\hline Koganei & $1 \mathrm{a}$ & $5 \cdot 2,4 \cdot 8$ & Seto et al. (1971) \\
\hline EM7 & $1 \mathrm{a}$ & $5 \cdot 2,4 \cdot 5$ & Takahashi et al. (1992) \\
\hline Fujisawa & $1 \mathrm{a}$ & $5 \cdot 2,4 \cdot 5$ & Takahashi et al. (1992) \\
\hline $422 / 1 \mathrm{E} 1$ & $1 b$ & $5 \cdot 2,4 \cdot 5$ & Takahashi et al. (1992) \\
\hline Tama-96 & 2 & $5 \cdot 2,4 \cdot 5$ & Zarkasie et al. (1996) \\
\hline Doggersharde & 4 & $5 \cdot 2,4 \cdot 5$ & Takahashi et al. (1992) \\
\hline Pécs 67 & 5 & $5 \cdot 2,4 \cdot 5$ & Takahashi et al. (1992) \\
\hline Dolphin E-1 & 6 & $5 \cdot 2,4 \cdot 5$ & Takahashi et al. (1992) \\
\hline Goda & 8 & $6 \cdot 5,3 \cdot 2$ & Takahashi et al. (1992) \\
\hline Kaperak & 9 & $5 \cdot 2,4 \cdot 5$ & Takahashi et al. (1992) \\
\hline IV12/8 & 11 & $5 \cdot 2,4 \cdot 5$ & Takahashi et al. (1992) \\
\hline Pécs 9 & 12 & $6 \cdot 5,3 \cdot 2$ & Takahashi et al. (1992) \\
\hline Pécs 3597 & 15 & $5 \cdot 2,4 \cdot 5$ & Takahashi et al. (1992) \\
\hline Tanzania & 16 & $6 \cdot 5,3 \cdot 2$ & Takahashi et al. (1992) \\
\hline 545 & 17 & $6 \cdot 5,3 \cdot 2$ & Takahashi et al. (1992) \\
\hline 2017 & 19 & $5 \cdot 2,4 \cdot 5$ & Takahashi et al. (1992) \\
\hline Bãno 36 & 21 & $5 \cdot 2,4 \cdot 5$ & Takahashi et al. (1992) \\
\hline MEW22 & $\mathrm{N}$ & $6 \cdot 5,3 \cdot 2$ & Takahashi et al. (1992) \\
\hline \multicolumn{4}{|c|}{ Ery. tonsillarum } \\
\hline Witlling & 3 & - & Takahashi et al. (1992) \\
\hline ATCC 43339 & 7 & - & Takahashi et al. (1992) \\
\hline Lengyel-P & 10 & - & Takahashi et al. (1992) \\
\hline Iszap-4 & 14 & - & Takahashi et al. (1992) \\
\hline 2553 & 20 & - & Takahashi et al. (1992) \\
\hline Bãno 107 & 22 & - & Takahashi et al. (1992) \\
\hline KS20A & 23 & - & Takahashi et al. (1992) \\
\hline \multicolumn{4}{|c|}{ Erysipelothrix spp. } \\
\hline Pécs 56 & 13 & $5 \cdot 2,4 \cdot 5$ & Takahashi et al. (1992) \\
\hline 715 & 18 & $6 \cdot 5,3 \cdot 2$ & Takahashi et al. (1992) \\
\hline
\end{tabular}

"Fragments detected in Southern blots of BamHI-digested genomic DNA using the HindIII fragment of $\mathrm{pHLY}$ as a probe.

Plasmid construction. Fig. 1 shows the plasmids used in this study. The vector plasmid pHY300PLK was used to construct a library of genomic DNA of Ery. rhusiopathiae strain Tama96 partially digested with Sau3AI. E. coli transformants from the library were spread on blood agar plates supplemented with ampicillin $\left(150 \mu \mathrm{g} \mathrm{ml}^{-1}\right)$ to detect colonies from the library showing haemolytic activity. Deletion derivatives shown in Fig. 1 were derived by restriction endonuclease digestion of pHLY.

Expression of haemolytic protein and its detection. A Bam $\mathrm{HI}$ linker was inserted into the SpeI site of pHLY (Fig. 1), and then a BamHI-HindIII DNA fragment was cloned into the BamHI and HindIII sites of pQE30 (Qiagen) to yield pQEHLY. The polyhistidine-tagged fusion protein was purified according to the manufacturer's instructions using the QIAexpress system and used to immunize rabbits to make rabbit polyclonal antibody against the fusion protein (anti-Hly). Using anti-Hly, Western blotting was performed with Erysi- pelothrix and E. coli strains. Antigens were prepared from bacterial cell pellets and culture supernatants. Briefly, $1 \mathrm{ml}$ of the bacterial cell culture was centrifuged, the supernatant was collected, and the bacterial cell pellet was suspended in $200 \mu \mathrm{l}$ protein lysis buffer (0.125 M Tris/Cl, pH 6.8, 4\% SDS, $20 \%$ glycerol, $0.042 \%$ bromophenol blue, $5 \%$ mercaptoethanol). The supernatant was mixed with $50 \mu \mathrm{l} 100 \%$ trichloroacetic acid, and after centrifugation precipitated protein was resuspended in $20 \mu \mathrm{l}$ lysis buffer. Protein suspensions were heated at $100^{\circ} \mathrm{C}$ for $5 \mathrm{~min}$, and then $10 \mu \mathrm{l}$ of each suspension was loaded on a $20 \%$ SDS-PAGE gel.

Haemolysis experiments. The polyhistidine-tagged fusion protein and PBS-washed E. coli MC1061 cells carrying pHLY were suspended in $200 \mu \mathrm{l}$ PBS at concentrations of $1.0 \mathrm{mg} \mathrm{ml}^{-1}$ and $1 \times 10^{8}$ cells $\mathrm{ml}^{-1}$, respectively. Then the solutions were incubated with a $1 \%(\mathrm{v} / \mathrm{v})$ suspension of sheep red blood cells at $37^{\circ} \mathrm{C}$ for $1 \mathrm{~h}$. Unlysed cells were removed by centrifugation at $740 \mathrm{~g}$. The amount of lysis was determined by measuring 


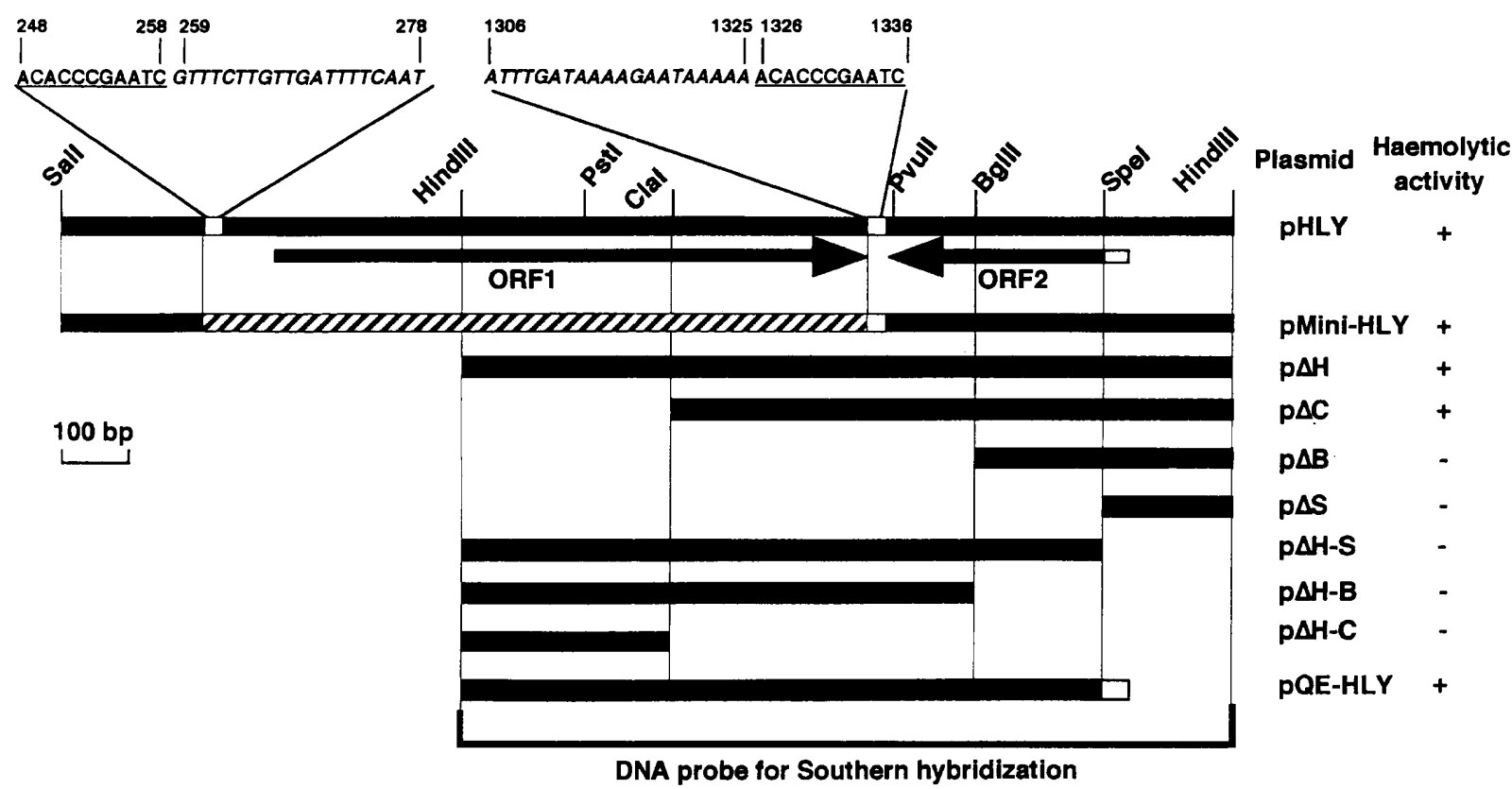

Fig. 1. Physical map of $\mathrm{pHLY}$ and its deletion derivatives. Haemolytic activity on blood agar plates of $E$. coli carrying the plasmids is indicated by + (positive) or - (negative). DNA sequences shown are the regions bounding the deletion in pMini-HLY, with numbers indicating the distance from the Sall site. Underlined and italic sequences are DR and inverted repeat sequences, respectively. The hatched box shows the region deleted in pMini-HLY. The open box in ORF2 shows the deduced signal sequence and the open box in PQE-HLY indicates the signal sequence of pQE30. The open boxes in pHLY and pMini-HLY indicate DRs and thick black lines show the regions cloned in deletion plasmids. The arrows show the orientation of the ORFs.

the $A_{570}$ of released haemoglobin spectrophotometrically. $E$. coli O157:H7 EDL933 and MC1061 were used as positive and negative controls, respectively.

Southern hybridization. Total DNA was purified from Erysipelothrix species strains as described by Makino et al. (1994) and digested with BamHI. Fragments were electrophoresed in an agarose gel, blotted onto nylon membrane (Schleicher \& Schuell) and then probed with a HindIII DNA fragment ( $\mathrm{p} \Delta \mathrm{H}$; Fig. 1) labelled with DIG-dUTP (Roche Diagnostics). Hybridization was performed in hybridization buffer containing $50 \%(\mathrm{v} / \mathrm{v})$ formamide at $42{ }^{\circ} \mathrm{C}$ according to the manufacturer's manual, and the DIG Luminescent Detection kit (Roche Diagnostics) was used for the detection of hybridized DNA.

Surface-labelling experiments. Ery. rhusiopathiae strain Tama-96 cells grown in BHIT were washed once with PBS and resuspended in PBS. Anti-Hly was added to the suspension, and the mixture was incubated at $37^{\circ} \mathrm{C}$ for $1 \mathrm{~h}$. Then bacterial cells were washed three times with PBS and resuspended in PBS, then incubated with anti-rabbit IgG conjugated to FITC. The cells were washed five times with PBS and examined with a fluorescence microscope. Rabbit polyclonal antibody against the surface protein SpaA (Makino et al., 1998) of Ery. rhusiopathiae was used as a positive control for surface labelling.

DNA sequencing and other techniques. The DNA sequences of the cloned fragments were determined using an ABI PRISM 377 (Applied Biosystems) DNA sequencer. Plasmid DNA isolation, agarose gel electrophoresis, SDS-PAGE and transformation of $E$. coli were done by the methods of Maniatis $e t$ al. (1982). Database searches with amino acid sequences used the FASTA program in the DDBJ. Vaccination using the ORF2 product and challenge with the Tama-96 strain were performed as described by Makino et al. (1998).

\section{RESULTS AND DISCUSSION}

\section{Isolation of a plasmid inducing haemolysis and its genetic analysis}

E. coli clones from the Tama-96 gene library were spread on blood agar plates to select colonies showing haemolysis $\left(\mathrm{Hly}^{+}\right)$. Two clones were independently isolated, and one of them, pHLY, was used for this study (Fig. 2). Deletion mutants were constructed using the restriction enzyme cleavage sites in pHLY to find the region essential for haemolytic activity. In addition, when E. coli MC1061 containing pHLY was spread on a blood agar plate supplemented with ampicillin, the plasmid pMini-HLY was generated spontaneously by deletion of about $1 \mathrm{~kb}$ from pHLY. The spontaneous deletion mutant still induced haemolysis (Fig. 1). The region essential for the haemolytic activity of pHLY was located within a $0.5 \mathrm{~kb}$ fragment containing the PvuII and HindIII sites (Fig. 1).

To characterize the gene essential for haemolysis and the deletion which generated pMini-HLY, the nucleotide sequences of the cloned regions in pHLY and pMiniHLY were determined. Two ORFs were identified in 


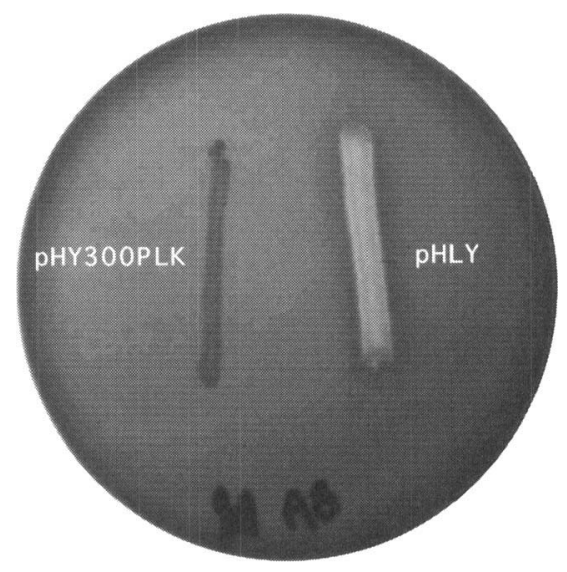

Fig. 2. Haemolytic activity on blood agar plates of pHY300PLK and $\mathrm{pHLY}$ in E. coli MC1061.

pHLY (Fig. 1). ORF1 encoded 313 amino acids to give a predicted $37 \mathrm{kDa}$ product and ORF2 encoded 149 amino acids, predicting a $16.2 \mathrm{kDa}$ product. A deletion of 1078 bp had generated pMini-HLY from pHLY (Fig. 1). The results demonstrated that ORF2 was associated with haemolysis (Fig. 1).

To understand the mechanism generating the deletion in pMini-HLY, the stability of pHLY in E. coli MC1061 $\mathrm{RecA}^{+}$and HB101 RecA ${ }^{-}$was examined by subculturing for about 20 generations in $L$ broth supplemented with ampicillin $\left(50 \mu \mathrm{g} \mathrm{ml}^{-1}\right)$. When plasmids carried in 10 $\mathrm{Hly}^{+}$colonies of each host strain were examined, pHLY was found to be stable in the RecA ${ }^{-}$host, but eight of ten $\mathrm{Hly}^{+}$colonies from the RecA ${ }^{+}$host had plasmids with molecular masses similar to pMini-HLY, as determined by agarose gel electrophoresis (data not shown).

Two direct repeat (DR) sequences of 11 bp (ACACCCGAATC) were found bracketing the deleted region in pHLY, and pMini-HLY carried only one DR (Fig. 1). The deleted region in the eight deletion plasmids obtained by subculturing the $\mathrm{RecA}^{+}$host strain was identical to that in pMini-HLY from DNA sequence analysis (data not shown). These results suggest that deletion of ORF1 to give pMini-HLY occurred by $\mathrm{RecA}^{-}$-dependent homologous recombination between DRs (Fig. 1).

\section{ORF1 is homologous to IS30 transposases}

A database search for sequences similar to ORF1 found that the sequence of the $\mathrm{C}$-terminal region from $\mathrm{P}_{142}$ had $30 \cdot 7-35 \cdot 7 \%$ identity to the sequences of the C-terminal region of the transposases of IS4351 (Smith, 1987), IS30 (Dalrymple et al., 1984), IS1161 (Giffard et al., 1993), IS1070 (Vaughan \& de Vos, 1995) and IS1139 (Lortie et al., 1994), which are insertion elements of the IS30 family. In addition, at both ends of a $1067 \mathrm{bp}$ region bracketed by two DRs in pHLY, two inverted repeat sequences of $20 \mathrm{bp}$, which were $50 \%$ identical to each

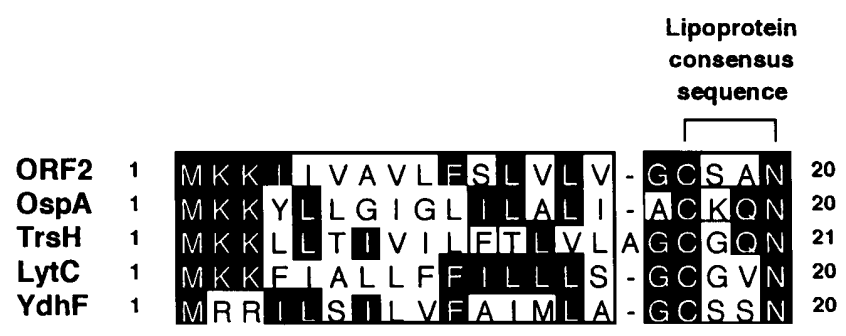

Fig. 3. Alignment of the 20 -amino-acid $\mathrm{N}$-terminal segment of the ORF2 product with related sequences. Boxes and black shading indicate residues that are similar or identical, respectively, as determined using SeqVu version 1.1 from the Garvan Institute of Medical Research, Sydney, Australia.

other, were detected (Fig. 1). These findings suggest ORF1 may function as a transposase, and the region deleted from pHLY may be the first insertion element identified in Ery. rhusiopathiae. We have not yet confirmed that the element is able to transpose. Since the sequences of the inverted repeats were only $50 \%$ identical to each other, it is likely that the frequency of its transposition may be extremely low even if the ORF1 product has a transposase activity (Mahillon \& Chandler, 1998).

\section{Characteristics of the haemolysin}

Although we were unable to identify sequences with significant similarity to ORF2 in the database, the protein it encoded was predicted by the PROST program (Nakai \& Kanehisa, 1991) to be secreted and acylated, with a signal peptidase II cleavage site between $G_{16}$ and $\mathrm{C}_{17}$ (Fig. 3). Although $\mathrm{p} \Delta \mathrm{H}-\mathrm{S}$, in which the first $42 \mathrm{bp}$ of ORF2 were deleted, did not induce haemolytic activity, pQE-HLY, with the same deletion but the remainder of the ORF2 coding sequence fused in-frame to the signal sequence of $\mathrm{pQE} 30$, induced haemolysis in E. coli (Fig. 1). The 20-amino-acid N-terminal sequence of the protein encoded by ORF2 was very similar to the Nterminal ends of OspA (Dykhuizen et al., 1993; Will et al., 1995), TrsH (Morton et al., 1993), LytC (Kunst et al., 1997; Lazarevic et al., 1992) and YdhF (Kunst et al., 1997), all of which contain the lipoprotein consensus sequence (von Heijne, 1989) (Fig. 3). In addition, computer prediction (Chou \& Fasman, 1978) of the amino acid secondary structure suggested that a $\beta$-turn may occur after the $\mathrm{C}_{17}$ putative acylation site in an 11amino-acid peptide which contains $\mathrm{S}_{18}, \mathrm{~N}_{20}$ and $\mathrm{N}_{22}$, indicating that the ORF2 product may be an efficient processed prolipoprotein (Hayashi \& Wu, 1990). Thus, ORF2 might encode a lipoprotein with haemolytic activity. However, haemolysis was not detected when purified polyhistidine-tagged $16 \mathrm{kDa}$ protein or PBSwashed E. coli cells containing pHLY were incubated with sheep red blood cells (data not shown). Thus it is possible that the $16 \mathrm{kDa}$ protein might not be a haemolysin, but rather facilitate haemolytic activity.

Using anti-Hly, Western blot analysis was performed to 
(a)

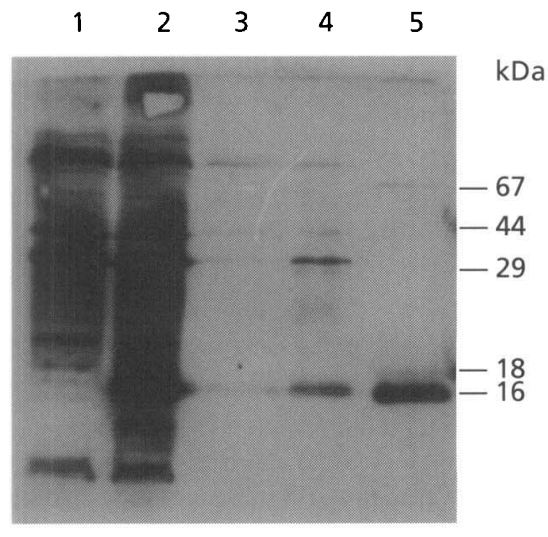

(b)

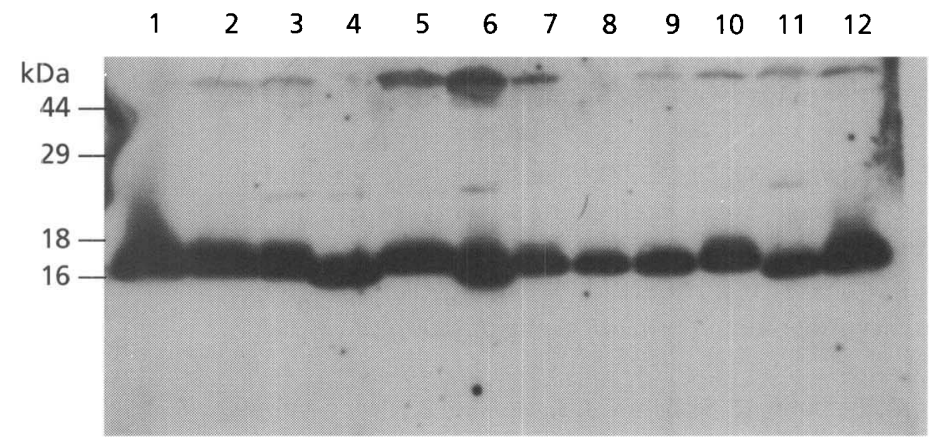

$\begin{array}{lllllllllll}13 & 14 & 15 & 16 & 17 & 18 & 19 & 20 & 21 & 22 & 23\end{array}$

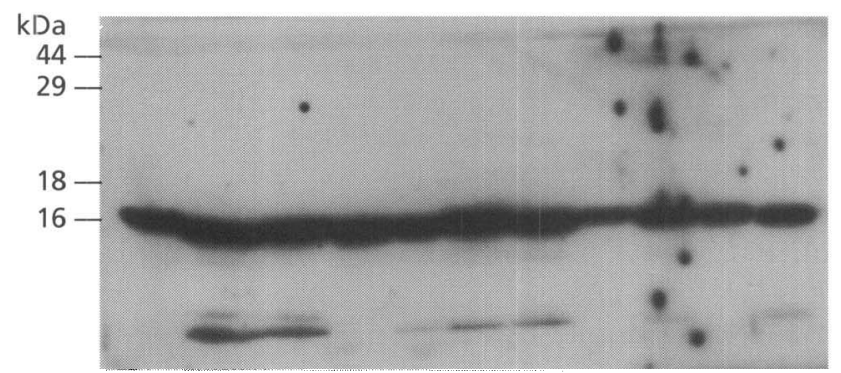

Fig. 4. Western blot analysis of E. coli MC1061 and Erysipelothrix strains. (a) Expression of the 16 kDa protein was examined by Western blotting of E. coli MC1061 harbouring PHY300PLK (lanes 1 and 3) and pHLY (lanes 2 and 4). Bacterial cell pellets (lanes 1 and 2) and culture supernatants (lanes 3 and 4) and purified fusion protein (lane 5) were used as antigens. (b) Expression of the $16 \mathrm{kDa}$ protein was examined by Western blotting of Erysipelothrix strains. Bacterial cell pellets from 23 Erysipelothrix strains were used as antigens: 1, Tama-96; 2, Fujisawa; 3, Doggersharde; 4, Pécs 67; 5, Dolphin E-1; 6, Goda; 7, Kaperak; 8, IV12/8; 9, Pécs 9; 10, Pécs 3597; 11, Tanzania; 12, 545; 13, 2017; 14, Bãno $36 ; 15$, Witlling; 16, ATCC 43339; 17, Lengyel-P; 18, Iszap-4; 19, 2553; 20, Bãno 107; 21, KS20A; 22, Pécs 56; $23,715$.

examine the production of the $16 \mathrm{kDa}$ protein. The expression of a protein which reacted with anti-Hly was examined in E. coli carrying pHLY (Fig. 4a). The protein was not detected in $E$. coli carrying the vector pHY300PLK (Fig. 4a, lanes 1 and 3), but was detected in the bacterial cell pellets and the culture supernatant of $E$. coli carrying pHLY (Fig. 4a, lanes 2, 4 and 5). Most of the protein reacting with anti-Hly was detected in the $E$. coli cell lysate, rather than in the culture supernatant (Fig. 4a, lanes 2 and 4). Proteins reacting with anti-Hly were detected in all strains of Erysipelothrix species tested, although there were some variations in apparent molecular mass (Fig. 4b; Table 1). Pre-immune serum did not react with Erysipelothrix strains and anti-Hly did not react with other pathogenic bacterial species, including L. monocytogenes, Staphylococcus aureus, Corynebacterium pseudotuberculosis, Streptococcus pneumoniae, Streptococcus suis, Bacillus anthracis, Actinobacillus pleuropneumoniae, Vibrio parahaemolyticus, Yersinia pseudotuberculosis, Aeromonas sp., Salmonella choleraesuis and enterohaemorrhagic E. coli (data not shown). Most of the reactive protein was detected in the bacterial cell fraction of Erysipelothrix strains, and live Erysipelothrix cells could be labelled with anti-Hly using anti-rabbit IgG conjugated to FITC (data not shown). This suggests that the $16 \mathrm{kDa}$ protein is probably a cell surface protein which is commonly distributed amongst Erysipelothrix species. Since a surface protein of Ery. rhusiopathiae, SpaA, was shown to induce protective immunity in mice (Makino et al., 1998 ), we thought that the $16 \mathrm{kDa}$ protein commonly distributed in Erysipelothrix species might also induce protective immunity. However, purified $16 \mathrm{kDa}$ protein or live E. coli cells carrying pHLY did not induce protective immunity in mice and serum from convalescent mice did not react with the $16 \mathrm{kDa}$ protein (data not shown). In addition, although the HindIII fragment of pHLY hybridized to two genomic BamHI fragments of all strains of Ery. rhusiopathiae and two other Erysipelothrix strains (Fig. 1; Table 1), none of the Erysipelothrix tonsillarum strains hybridized to this probe. Thus although Ery. tonsillarum produced a $16 \mathrm{kDa}$ protein reactive with antibody against the ORF2 product from Ery. rhusiopathiae, the gene had lower levels of sequence similarity, and the IS30-like element was also not detected in Ery. tonsillarum. Although we were unable to clarify the function of the $16 \mathrm{kD}$ a protein, our results are suggestive of a role as a surface protein involved in haemolysis in all Erysipelothrix species.

\section{ACKNOWLEDGEMENTS}

This work was supported in part by a grant from the Akiyama Foundation. 


\section{REFERENCES}

Bielecki, J., Youngman, P., Connelly, P. \& Portnoy, D. A. (1990). Bacillus subtilis expressing a haemolysin gene from Listeria monocytogenes can grow in mammalian cells. Nature 345, 175-176.

Chou, P. Y. \& Fasman, G. D. (1978). Prediction of the secondary structure of proteins from their amino acid sequence. $A d v$ Enzymol Relat Areas Mol Biol 47, 45-148.

Dalrymple, B., Caspers, P. \& Arber, W. (1984). Nucleotide sequence of the prokaryotic mobile genetic element IS30. EMBO J 3, 2145-2149.

Dykhuizen, D. E., Polin, D. S., Dunn, J. J., Wilske, B., Preac-Mursic, V., Dattwyler, R. J. \& Luft, B. J. (1993). Borrelia burgdorferi is clonal: implications for taxonomy and vaccine development. Proc Natl Acad Sci USA 90, 10163-10167.

Giffard, P. M., Rathsam, C., Kwan, E., Kwan, D. W., Bunny, K. L., Koo, S. P. \& Jacques, N. A. (1993). The $f t f$ gene encoding the cellbound fructosyltransferase of Strepiococcus salivarius ATCC 25975 is preceded by an insertion sequience and followed by FUR1 and $c l p P$ homologues. J Gen Microbiol 139, 913-920.

Hayashi, S. \& Wu, H.C. (1990). Lipoproteins in bacteria. J Bioenerg Biomembr 22, 451-471.

von Heijne, G. (1989). The structure of signal peptides from bacterial lipoproteins. Protein Eng 2, 531-534.

Kunst, F., Ogasawara, N., Moszer, I. and 148 other authors (1997). The complete genome sequence of the Gram-positive bacterium Bacillus subtilis. Nature 390, 249-256.

Lazarevic, V., Margot, P., Soldo, B. \& Karamata, D. (1992). Sequencing and analysis of the Bacillus subtilis lytRABC divergon: a regulatory unit encompassing the structural genes of the $\mathrm{N}$-acetylmuramoyl-L-alanine amidase and its modifier. J Gen Microbiol 138, 1949-1961.

Lortie, L. A., Gagnon, G. \& Frenette, M. (1994). IS1139 from Streptococcus salivarius: identification and characterization of an insertion sequence-like element related to mobile DNA elements from gram-negative bacteria. Plasmid 32, 1-9.

Mahillon, J. \& Chandler, M. (1998). Insertion sequences. Microbiol Mol Biol Rev 62, 725-774.

Makino, S.-I., Okada, Y., Maruyama, T., Ishikawa, K., Takahashi, T., Nakamura, M., Ezaki, T. \& Morita, H. (1994). Direct and rapid detection of Erysipelothrix rhusiopathiae DNA in animals by PCR. J Clin Microbiol 32, 1526-1531.

Makino, S.-I., Murakami, S., Yamamoto, K., Shirahata, T., Sawada, T., Wakamoto, H. \& Morita, Y. (1998). Properties of repeat domain found in a novel protective antigen, SpaA, of Erysipelothrix rhusiopathiae. Microb Pathog 25, 101-109.

Maniatis, T., Fritsch, E. F. \& Sambrook, J. (1982). Molecular Cloning: a Laboratory Manual. Cold Spring Harbor, NY: Cold Spring Harbor Laboratory.

Morton, T. M., Eaton, D. M., Johnston, J. L. \& Archer, G. L. (1993). DNA sequence and units of transcription of the conjugative transfer gene complex (trs) of Staphylococcus aureus plasmid pGO1. J Bacteriol 175, 4436-4447.

Nakai, K. \& Kanehisa, M. (1991). Expert system for predicting protein localization sites in Gram-negative bacteria. Proteins 11, 95-110.

Seto, K., Nishimura, Y., Fujiki, M., Azechi, H. \& Suzuki, K. (1971). Studies on acriflavine fast attenuated Erysipelothrix insidiosa. Comparison on pathogenicity and immunogenicity between mice and pigs. Jpn J Vet Sci 33, 161-171.

Smith, C. J. (1987). Nucleotide sequence analysis of Tn4551: use of ermFS operon fusions to detect promoter activity in Bacteroides fragilis. J Bacteriol 169, 4589-4596.

Stanley, P., Koronakis, V. \& Hughes, C. (1998). Acylation of Escherichia coli hemolysin: a unique protein lipidation mechanism underlying toxin function. Microbiol Mol Biol Rev 62, 309-333.

Takahashi, T., Fujisawa, T., Tamura, Y., Suzuki, S., Muramatsu, M., Sawada, T., Benno, Y. \& Mitsuoka, T. (1992). DNA relatedness amongst Erysipelothrix rhusiopathiae strains representing all twenty-three serovars and Erysipelothrix tonsillarum. Int J Syst Bacteriol 42, 469-473.

Vaughan, E. E. \& de Vos, W. M. (1995). Identification and characterization of the insertion element IS1070 from Leuconostoc lactis NZ6009. Gene 155, 95-100.

Will, G., Jauris-Heipke, S., Schwab, E., Busch, U., Roessler, D. Soutschek, E., Wilske, B. \& Preac-Mursic, V. (1995). Sequence analysis of ospA genes shows homogeneity within Borrelia burgdorferi sensu stricto and Borrelia afzelii strains but reveals major subgroups within the Borrelia garinii species. Med Microbiol Immunol 184, 73-80.

Wood, R. L. (1984). Swine erysipelas - a review of prevalence and research. J Am Vet Med Assoc 184, 944-948.

Zarkasie, K., Sawada, T., Yoshida, T., Takahashi, I. \& Takahashi, T. (1996). Growth ability and immunological properties of Erysipelothrix rhusiopathiae serotype 2. J Vet Med Sci 58, 87-90.

Received 14 September 1998; revised 10 February 1999; accepted 24 February 1999. 